\title{
What should be done about smoking in movies?
}

\section{Simon Chapman}

In 1997 Ron Davis, Tobacco Control's inaugural editor, and I wrote an editorial titled Smoking in movies: is it a problem ${ }^{1}$ Since then, a growing body of research has examined the relation between viewing of movies containing depictions of smoking and subsequent smoking among youth. Reviewing this evidence, a 2008 National Cancer Institute monograph concluded "The depiction of cigarette smoking is pervasive in movies, occurring in threequarters or more of contemporary boxoffice hits. Identifiable cigarette brands appear in about one-third of movies. The total weight of evidence from crosssectional, longitudinal and experimental studies indicates a causal relationship between exposure to depictions of smoking in movies and youth smoking initiation." ${ }^{\prime 2}$ The report's conclusion is consistent with commonsense and should give major impetus to what is a growing debate. If the highly choreographed imagery of tobacco advertising influences the uptake of smoking, then so will widespread positive depictions of smoking in movies, now arguably rivalling direct tobacco advertising as the world's largest vector for sustaining the appeal of smoking. Smoking in movies is a problem.

So what might be done about it? Many nations ban all tobacco advertising because of its influence on smoking. The idea that movies with smoking scenes should similarly be either banned or at least regulated through adult-only classification has gained traction in a small number of nations, particularly India, Thailand and the United States. The debate remains nascent elsewhere, with few signs of government interest.

In this commentary, I critically review three of the most prominent strategies proposed as ways of controlling smoking in movies. I caution that banning smoking from movies constitutes a fundamental threat to freedom of expression, inviting unavoidable ridicule for the inconsistencies and "airbrushing of reality" that its adoption would unleash. This is likely to

Correspondence to: Professor Simon Chapman, School of Public Health Edward Ford Building A27 University of Sydney, Sydney, NSW 2006, Australia; sc@med.usyd. edu.au alienate many ordinary and influential people who would otherwise be strongly supportive of comprehensive and tough tobacco control. I conclude that nations should pass or amend laws to require "no product placement" disclosures; global efforts should be increased to expose the extent and consequences of smoking in movies; and whistleblowers should be encouraged to expose instances of tobacco industry inducements to the movie industry so that prosecutions can arise where possible. Efforts should continue to persuade directors to be more judicious in their use of gratuitous smoking where this is unnecessary to the verisimilitude of their productions. And finally, smoking should become one element taken into account in film classification, but as occurs now with film rating classification in relation to other adult elements, it should be considered in overall context on a case-by-case basis rather than triggering automatic upward classification.

\section{IS TOBACCO PRODUCT PLACEMENT STILL OCCURRING?}

Movies have long been prized vehicles for manufacturers to promote their products. When prominent actors smoke in box office hits, powerful and indelible associations are added to smoking. Globally, hundreds of millions of young people view these movies every year, often regardless of their rating status. No one should therefore be surprised that the tobacco industry has a long history of promoting both smoking and particular brands by inducing producers to show products in the hands and between the lips of leading actors. ${ }^{3}$ While the US-based tobacco industry has denied since 1990 that it continues product placement in movies, and the 1998 Master Settlement Agreement, which the major companies have signed, expressly outlaws the practice, ${ }^{4}$ few experienced with the tobacco industry's track record trust these assurances. Orthodox tobacco promotional avenues are being closed through spreading national advertising bans and the tobacco industry actively exploits legislative loopholes in new media. ${ }^{5}$ It would therefore be astonishing if tobacco interests were not still surreptitiously funding movie producers via third parties to have actors smoke in movies with major appeal to the industry's most important market segments, especially youth.

If this could be shown to be occurring in the United States, it would be simply another form of tobacco advertising, breaching undertakings in the Master Settlement Agreement. ${ }^{4}$ If occurring in movie production in the increasing number of nations with laws incorporating comprehensive definitions of what constitutes tobacco advertising, it would be prosecutable. Yet no such prosecutions have occurred. If paid product placement is indeed ongoing and as widespread as some tobacco control advocates imply, with myriads of directors insisting that actors smoke, it is also significant that no whistleblowers have emerged with examples of recent movies in which such inducements occurred. The movie industry contains many powerful individuals who would be appalled by such activity and who doubtless would like to expose such conduct if indeed it were happening.

Some tobacco control advocates see a movie cigarette and conclude "tobacco industry!" Sometimes it may well be, but often it is not, anymore than every time we see a car in a movie we should feel obliged to conclude "automobile industry!" People smoke, just as people drive, drink and eat. Film makers reflect this.

An equally plausible explanation for smoking in movies, therefore, is that many movie directors are attuned to the richly signifying semiotics of smoking ${ }^{6}$ and often judge that characters should smoke to convey particular associations. Here the options for control are far more complex. Three broad approaches have been proposed to reduce minors' exposure to smoking scenes in movies: banning all scenes of smoking (proposed, but now dormant after widespread opposition in India); de facto banning through pixilating the act of smoking and packs of cigarettes (Thailand); and one which appears to have the widest supportintroducing an " $\mathrm{R}$ " classificatory rating either via movie industry voluntary codes or by law, preventing children under 17 years from admission to movies depicting smoking unless accompanied by an adult (this is the US guideline). Stan Glantz's Smoke Free Movies website proposes an $\mathrm{R}$ rating thus: "Any film that shows or implies tobacco should be rated "R". The only exceptions should be when the presentation of tobacco clearly and 
unambiguously reflects the dangers and consequences of tobacco use or is necessary to represent the smoking of a real historical figure."

\section{BANNING ALL SMOKING IN MOVIES?}

Film, the internet, magazines, literature and newspapers have a long history of being seen by various interest groupspolitical, moral/religious and health-as vehicles that carry a diverse range of pernicious content said to be harmful to those exposed to it. Nations adopt a range of policies toward such content ranging from massive state control of all content (for example, North Korea and Myanmar (Burma)) through to large-scale active and passive censorship of material that offends political or religious sensibilities, as occurs routinely in many despotic, authoritarian and religiously fundamentalist nations.

At the opposite end of such policy are nations where freedom of speech and expression are enshrined as being of fundamental importance to the social and political fabric. In such nations, censorship-for whatever noble purpose-is met with principled resistance with the onus being on those demanding censorship to demonstrate that the case for intervention is strong, and that the consequences of exposure are very serious. The few examples here are absolute prohibitions on promoting terrorism and producing or displaying child pornography, and on the overt incitement of violence and racial vilification.

Those who see movies as essentially vehicles for the transmission of health authority-sanctioned content meet opposition from those who argue that the role of film in open societies is far wider than being simply a means of mass communication of desirable or healthy role models to young people. Many movies depict social problems, people behaving badly and the seamy side of life.

The role of cinema and literature is not simply to promote overtly pro-social or health "oughts" but to have people also reflect on what "is" in society or in screenwriters' imaginations. This includes a long list of disturbing, anti-social, dangerous and unhealthy realities. Numbered among these are domestic violence, animal cruelty, the exploitation of minorities, injustice, and neglect. Whether for educational purpose, entertainment or the broader purpose of artistic expression, filmmakers have often depicted highly socially undesirable activities such as racial hatred and vilification (for example, Schindler's List, Mississippi
Burning), genocide (Hotel Rwanda), gang violence (Romper Stomper, Clockwork Orange) and crime (choose from literally thousands). It would be ridiculously simplistic to assume that by showing something most would regard as undesirable, a filmmaker's purpose was always to endorse such activity. People learn in ways far more complex than being fed a continuous diet of wholesome role models. Many would deeply resent a view of movies that saw them as the equivalent of religious or moral instruction, to be controlled by those inhabiting the same values.

Moreover, hundreds of millions of people around the world smoke. It would be unprecedented for cinema to have to "pretend" that this reality was not the case by never showing smoking in any movie, thereby implying that it was as heinous as (for example) child pornography, but less of a problem than the commonplace murder, mayhem and violence seen in countless films. It would invite ridicule from many people within and beyond the health sector, who would see such a proscription on showing or mentioning smoking as an affront to freedom of speech. It is undoubtedly for this reason that the only nation that has sought to actually ban all smoking from movies (India) met with principled and successful resistance, including from many within the Indian civil society and arts communities.

Smoke Free Movies' concession that exceptions should be allowed for "real historical figures" who smoked (such as Churchill or Mao Tse-Tung) in R-rating is notable here. It acknowledges that cinema should not "airbrush" historical reality. What is left unexplained here, though, is why it is permissible for children to see known historical smokers smoking, but not smokers set in a period such as the 1950s when the reality of social life was that smoking was widespread and unrestricted. Or indeed, why it would not equally be airbrushing of reality to show smoking in a movie set today depicting a group of people from a social or cultural group where smoking was the norm and therefore an accurate aspect of their lives?

\section{PIXILATING SMOKING IN MOVIES?}

Thai law requires that any movie or programme broadcast on television showing cigarettes or smoking must pixilate the cigarettes. The reasoning here would appear to be that as long as people do not actually see a cigarette, somehow the normative message will not get through to audiences. Bungon Ritthiphakdee, a
Thai tobacco control expert, says that that local television, movie and drama producers today seldom script scenes of people smoking since the law was introduced, because the required pixilation adds an extra production cost and, more importantly, annoys viewers. Pixilation is therefore today largely confined to foreign produced, imported films.

Pixilation is common practice on television news crime reports: innocent until found guilty felons' faces are pixilated as they enter court before a trial. But is there anyone who doesn't think "there's the felon!" just as a pixilated cigarette would not immediately tell viewers that here was someone smoking? It is difficult to imagine what Thai health authorities think that not actually seeing the cigarette will achieve.

\section{R-RATE ALL SMOKING SCENES?}

In many liberal societies sexual, violent and illicit drug scenes in movies invoke classification as unsuitable for very young children, although there is considerable variation between nations about what is permissible to screen to children. Parents do not have time to research the content of all movies and value movie classifications as a way of helping them avoid inappropriate, possibly disturbing, content. This brings us to the widely supported proposal that smoking should not be banned in movies, but that all but manifestly anti-smoking scenes-even those where smoking is only "implied"-should cause a movie to be classified as "R". Under the Smoke Free Movies policy, this would mean that even one instance of smoking would see a movie classified as being equivalent to the Motion Picture Association of America's standard for those depicting "adult themes, adult activity, hard language, intense or persistent violence, sexuallyoriented nudity, drug abuse or other elements", "where such scenes are often sustained. Is this an equivalence that many in the community would find reasonable?

For example. the US-based Smoke Free Movies site ${ }^{7}$ currently rates the new Batman movie The Dark Knight as "promoting smoking" because, amid a cast of thousands, one minor character smokes a cigar. While activists dedicated to eradicating smoking in children's movies engage in organised complaining about such closely monitored incidents, it seems improbable that many ordinary citizens would spontaneously rise up in community protest about such minor usage in the way they would about the sort of 
sustained adult content that currently sees movies classified as unsuitable for children, should those movies be not so classified. In this respect, arguments based on the unacceptability to the community of any smoking scenes are highly unlikely to find widespread support and be seen as overly extreme solutions proposed by single-minded interest groups.

\section{SLIPPERY SLOPE PROBLEMS?}

In tobacco control, "slippery slope" or "thin end of the wedge" arguments have a long and disreputable history. For many years the tobacco industry used such arguments to trivialise the health risks of smoking, arguing (for example) that if health warnings were to go on cigarette packs, then they should also go on a large range of other ordinary products that might be harmful too, despite these often being of incomparably lower risk (see, for example, a long list of "dangerous" products gathered by Brown and Williamson in $1984^{\circ}$ ). Such sophistry, however, does not mean that problems of inconsistency are not problematic to the determination of reasonable social policy. If even a single instance of smoking were to consign a movie to $\mathrm{R}$ status because of its potential to influence children to smoke, immediate parallel questions arise about a wide range of other potentially adverse role modelling cues in films.

Smoking causes massive health problems, but in that it is not unique. Globally, large-scale health and social problems flow from many activities that also often appear in movies. These include crime, physical inactivity, over-eating, excessive use of alcohol, unsafe sex, speeding and dangerous driving, gambling, risk taking such as extreme sport and adventure, motor cycle use and helmet-less cycling. For example, by the same reasoning that movies showing smoking might normalise or glamorise tobacco use, it could be argued that film should never show positive scenes of gluttony or actors enthusiastically eating fast food because of the obesity epidemic and millions of overweight and obese children struggling to control their weight. Countless comedy scripts would need to go back to the drawing board. Scenes of people drinking alcohol might be excised from children's movies-particularly if those drinking seemed to be enjoying it-because this might seed inappropriate ideas about alcohol in tender minds. All car chases and speeding scenes of course would be restricted to adult movies.

Smoking cartoon characters have been fingered as unacceptable $e^{10}$ and a smoking
Babar the elephant and a pipe smoking Santa Claus have been condemned. ${ }^{11}$ So by the same concerns, why not also R-rate the maniacal Road Runner, whose disrespect for the highway code might be taken literally by the same innocent children?

These examples are not either facetious or hypothetical, but invite an "alphabet soup" of classificatory ratings, all respectful of the cases that could be mounted by other single issue health and social problem interest groups. For example, in August 2008, Dr. Martin Schiff, a US weight-loss expert called for movies promoting obesity to be classified "O" (for obesity): "Every day we see examples of overeating, gorging, food play and general disregard for health in movies and TV shows. No wonder millions of people are overweight." He nominated the familyoriented Abba musical Mamma Mia! for an "O" rating because it contained scenes of a lavish party and feast "where the participants seem to be eating anything and everything". ${ }^{12}$

Most will dismiss such calls as entirely unreasonable. But an illustration of how such inconsistency plays out in practice comes from scenesmoking.org which rates the 2008 What Happens in Vegas, starring Cameron Diaz, as a "thumbs up/pink lung" because it contains no smoking. However, it does contain binge drinking, failure to wear seat belts, intoxication leading to possibly unprotected sex, gambling and a parody of spousal abuse. With such a film receiving a ringing endorsement from this youth-friendly organisation, ordinary people might be entitled to ask about consistency.

If R-rating proponents succeeded in having all smoking scenes restricted to R-rated movies, would this keep most children from seeing them? Hardly, as children's access to R-rated and even Xrated movies is widespread. ${ }^{13}{ }^{14}$ A recent study showed that all 40 extremely violent movies were seen by a median of $12.5 \%$ of US adolescents aged 10-14 years. Blade, Training Day, and Scary Movie were seen, respectively, by $37.4 \%, 27.3 \%$ and $48.1 \%$ of the overall sample and $82.0 \%$, $81.0 \%$ and $80.8 \%$ of black male adolescents. ${ }^{15}$ R-rating may deplete box office takings, as R-rated movies are known to attract smaller audiences, but with rentals and downloaded movies easily accessible to children, it is doubtful whether fewer children in total would see them.

\section{DO ALL SCENES PROMOTE SMOKING?}

Another problem with R-rating movies with any smoking scenes other than those that openly proselytise against smoking in Surgeon General warning style, lies with R-classification proponents' beliefs that all depictions of smoking are self-evidently alluring, which is why they need classifying for adults only. This is a simplistic notion that could result in some powerful anti-smoking messages being kept away from children.

Consider two examples. An on-going story line from the immensely popular American TV series Friends (51 million watched the final episode in the US alone Friends. 2008, available from http://en. wikipedia.org/wiki/Friends) featured the character Chandler's attempts to quit smoking. Scenes included showing him smoking but the overall narrative was anti-smoking, despite scenes and lines often talking about the attractions of smoking. Any rule relegating any smoking to $\mathrm{R}$ would see children deprived of the benefit of seeing such memorable indictments of smoking. Those who want to banish such scenes from young eyes can thereby score some own-goals.

In In Her Shoes, starring Cameron Diaz, Toni Collette and Shirley MacLaine, Diaz plays the insect thin, dyslexic, rudderless younger sister of Collette's character. They have had an emotional roller-coaster of a childhood, and the film takes us through an emotional resolution as they become re-acquainted with their estranged grandmother (MacLaine). At one stage, Diaz reaches for a cigarette. The sagacious MacLaine says "you shouldn't smoke. You have a history of lung cancer in your family". MacLaine takes the cigarette away, as a grandmother can.

If the movement to get all non-historical depictions of smoking R-certificated succeeds, then this powerful moment would relegate the film to R-rating (supposing that its other content had not already caused this). If that happened, then perhaps many thousands of young people around the world, lured by Diaz's box office appeal, would be denied the richly contextualised and powerful message that the movie delivers: people who smoke are often very glamorous and cool, and drip with "attitude" but, like Diaz, they are often drifting, confused, and in the end, not particularly attractive characters. Why try to keep all this away from adolescents?

Such films present richly textured moral tales for young people to absorb and reflect on as they form their values and make decisions about matters like smoking. Only the crudest of early "hypodermic" media effects models ${ }^{16}$ 
could posit that a single glimpse of smoking will, Pied Piper fashion, lure children ineluctably into a life of smoking. Film classification panels understand the importance of context in assigning their classifications, and are unlikely to be convinced that even one glimpse of smoking in any film is so self-evidently unacceptable that such an inflexible formulaic approach is justified.

The Smoke Free Movies project specifies an exemption for smoking scenes "when the presentation of tobacco clearly and unambiguously reflects the dangers and consequences of tobacco use". This also seems an overly narrow guideline. For example, a family movie which featured an ongoing narrative about a mother struggling to quit, whose smoking upset her family, which saw the character exiled from friends by having to smoke in alleyways outside restaurants, and who expressed regret about having commenced could send a powerful anti-smoking message which would fall well short of the prescribed "health consequences" message.

\section{ALIENATING COMMUNITY SUPPORT}

For many years, tobacco control laboured to free itself from its early moralistic associations with dour temperance-based movements, ${ }^{17}$ close brethren of movements which routinely protested at licentious literature and film, modern dancing and other devil's work. In the United States, there is some evidence that Rratings for smoking in the manner described have substantial community support. ${ }^{18}$ But the United States is a nation with a broad rump of historical puritanism that is less evident in many nations. The mere popularity of a proposal should also not blind us to its shortcomings. Overly proscriptive, absolutist hostility to any sight of smoking in movies risks rekindling these historical associations, which may alienate many otherwise strong supporters of tobacco control and stimulate bitingly sarcastic diversions ${ }^{19}$ that could be avoided by more reasonable case-by-case policy.

\section{WHAT SHOULD BE DONE?}

There are legally important differences between commercial speech (such as advertising) and free speech of the sort contained in cultural expression like movies and literature, ${ }^{20} 21$ and any attempt to equate them as a basis for regulation, particularly on the basis of mere suspicion that the tobacco industry must be directing smoking scene traffic, will fail in most nations. But where product placement can be shown to be a direct result of tobacco industry promotional efforts, the matter crosses the line.

Whistleblowers have made invaluable contributions to tobacco control. Potential informants should be actively fostered to speak out about product placement and legal action taken against any companies found to be engaging in it for having broken the Master Settlement Agreement "No Participating Manufacturer may, beginning 30 days after the MSA Execution Date, make, or cause to be made, any payment or other consideration to any other person or entity to use, display, make reference to or use as a prop any Tobacco Product, Tobacco Product package, advertisement for a Tobacco Product, or any other item bearing a Brand Name in any motion picture, television show, theatrical production or other live performance, live or recorded performance of music, commercial film or video, or video game." $){ }^{4}$ Governments around the world should explicitly incorporate similar clauses in their tobacco advertising legislation.

The growing momentum of evidence so thoroughly summarised in the National Cancer Institute report should be publicised widely, with particular efforts to do this within the movie industry. This will accelerate critical discourse within the industry, which can only heighten awareness about its role in promoting smoking. Smoke Free Movies' efforts in this regard are exemplary although, as I have argued, likely to be generating unnecessary resistance from many because of their overly absolutist guidelines that all smoking, no matter how fleeting, should trigger an R-rating.

Concerns that outright bans on smoking in movies "airbrush reality" raise the serious concerns I have outlined. But equally serious is the paucity of movies where the health consequences of smoking are even mentioned, let alone dramatised. This is airbrushing in the opposite direction. Here, tobacco control advocates should not insist that all movies with smokers be obliged to show its consequences, because such insistence erroneously assumes that movies are essentially health promotion vehicles requiring sign-off from health panels. Adolescents who smoke very rarely get sick and die in adolescence, so such an insistence would throw up the ridiculous spectre of all such films having to add an epilogue showing what happened to the smokers in later life. But the public health community could encourage writers and directors to engage with health consequence subplots more often than they do now. Many social movements have successfully partnered with the movie industry to increase exposure to their issues.

The discourse about the responsibility of directors has already had an impact within the industry. The Walt Disney company's decision to no longer include any smoking in its family viewing fare will see the demise of the odd cigarchomping pirate in such movies. Few could object to such gestures. But few sensible people see the problem as being much to do with the occasional sight of a cigarette or pipe in overtly "family entertainment". The major challenge comes with adolescent-targeted movies where smoking can have a major presence. As I have argued, it is difficult to be categorical that any smoking in a movie must mean that all such movies "promote" smoking.

But it is undeniable that many such movies do, with the exact same consequences for the health of millions that were invoked as justification for controlling tobacco advertising. If the more reasonable proposition were promoted that smoking ought to be considered as one element within movie rating panels' assessments of how a movie should be rated, I would predict that many within government and the movie industry would be more receptive and more progress would be made.

Funding: This paper was supported by a National Health and Medical Research Council (Australia) grant on the future of tobacco control (№ 401558).

Competing interests: None.

Tobacco Control 2008;17:363-367.

doi:10.1136/tc.2008.027557

\section{REFERENCES}

1. Chapman $\mathbf{S}$, Davis RM. Smoking in movies: is it a problem? Tob Control 1997;6:269-71.

2. National Cancer Institute. The role of the media in promoting and reducing tobacco use. Bethesda, MD: US Department of Health and Human Services, National Institutes of Health, National Cancer Institute, June 2008. NIH Publication No 07-6242

3. Lum KL, Polansky JR, Jackler RK, et al. Signed, sealed and delivered: Big Tobacco in Hollywood, 1927-1951 Tob Control 2008;17:313-23.

4. National Association of Attorneys General. Master Settlement Agreement. 1998. Available from: http://www.naag.org/backpages/naag/tobacco/msa/ msa-pdf/1109185724 1032468605 cigmsa.pdf

5. Freeman B, Chapman S. Tobacco promotion invades new media. Lancet Oncol 2007;8:973-4.

6. Klein R. Cigarettes are sublime. Durham: Duke University Press, 1993.

7. SmokeFree Movies. Available from http:// smokefreemovies.ucsf.edu (accessed 28 Aug 2008).

8. Motion Picture Association of America. Classification and rating rules 2007. Available from: http://www.mpaa.org/Ratings_Rules.pdf

9. Brown, Williamson. Health hazards. 1984. Available from: http://legacy.library.ucsf.edu/tid/blr93f00 
10. Nakahara S, Ichikawa M, Wakai S. Smoking scenes in Japanese comics: a preliminary study. Tob Control 2005; 14:71.

11. Nakahara S, Wakai S, Ichikawa M. Smoking in children's picture books. Tob Control 2003:12:110.

12. Hiscock J. 0 for obesity at the snack bar. National Post (Canada) 200816 Aug.

13. Jackson C, Brown JD, L'Engle KL. R-rated movies, bedroom televisions, and initiation of smoking by white and black adolescents. Arch Pediatr Adolesc Med 2007;161:260-8

14. Wingood GM, DiClemente RJ, Harrington $\mathrm{K}$, et al. Exposure to $\mathrm{X}$-rated movies and adolescents' sexual and contraceptive-related attitudes and behaviors. Pediatrics 2001:107:1116-9.

15. Worth KA, Gibson Chambers J, Nassau DH, et al Exposure of US adolescents to extremely violent movies. Pediatrics 2008:122:306-12.

16. Wartella $\mathbf{E}$, Reeves B. Historical trends in research on children and the media 1900-1960. J Commun 1985; 35:118-33.

17. Tyrrell I. Deadly enemies. Tobacco and its opponents in Australia. Sydney: UNSW Press, 1999.

18. McMillen R, Tanski S, Winickoff J, et al. Attitudes about smoking in the movies. Social Sciences

Research Center, Mississippi State University, 2007.
Available from: http://www.ssrc.msstate.edu/ socialclimate/Site/Home files/

Attitudes Smoking Movies.pdf

19. Queenan J. Hollywood stogies. Wall Street Journal 2008 June 21;Section A9.

20. Gostin LO. Corporate speech and the constitution: the deregulation of tobacco advertising. Am J Public Health 2002;92:352-5.

21. Bayer R, Gostin LO, Javitt GH, et al.

Tobacco advertising in the United States: a proposal for a constitutionally acceptable form of regulation. JAMA 2002:287: $2990-5$.

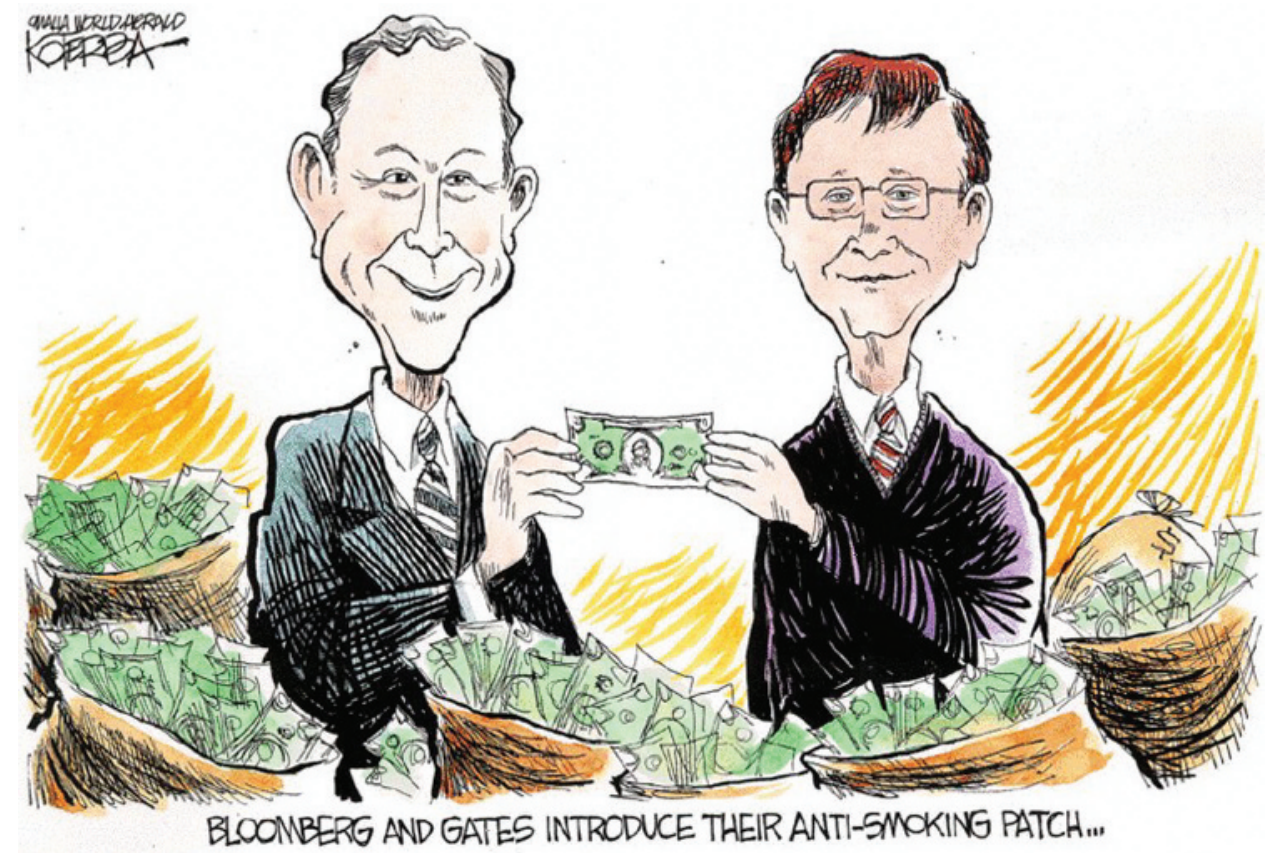

(c) Koterba, Omaha World-Herald, 2008. 